Andrew J. Larner

Received: 18 April 2006

Accepted in revised form: 12 May 2006

Published online: 15 June 2006

\author{
A.J. Larner (两) \\ Walton Centre for Neurology \\ and Neurosurgery, \\ Lower Lane, Fazakerley, \\ Liverpool L9 7LJ, UK \\ e-mail: a.larner@thewaltoncentre.nhs.uk \\ Fax: +44-151-529-5513
}

\section{Late presentation of primary headache associated with sexual activity: is non-invasive angiography worthwhile?}

\author{
Abstract The place of angiography \\ in late presentation of headache \\ associated with sexual activity has \\ not been defined, unlike the situa- \\ tion with acute presentations. In a \\ cohort of patients fulfilling diag- \\ nostic criteria for primary \\ headache associated with sexual \\ activity and presenting late (at \\ least three weeks after headache \\ onset), those undergoing non-inva-
}

sive angiography showed no abnormalities. It is suggested that noninvasive angiography is not routinely indicated in late presentations of headache associated with sexual activity.

Key words Headache associated with sexual activity $\cdot$ Non-invasive angiography

\section{Introduction}

In the second edition of the International Headache Society (IHS) classification of headache disorders, primary headache associated with sexual activity (PHSA) is subdivided into preorgasmic headache (4.4.1) and orgasmic headache (4.4.2) [1], corresponding to the categories of headache associated with sexual activity types 1 ("dull") and 2 ("explosive") in the first edition of the IHS classification [2]. The classification notes that on first onset of orgasmic headache it is mandatory to exclude conditions such as subarachnoid haemorrhage $(\mathrm{SAH})$ and arterial dissection, because of the clinical similarity of these headaches [1]. Although described [3, 4], secondary or symptomatic sexual headaches are probably rare. Catheter angiography was negative in all nine patients examined in the study by Lance [5]. In a cohort of 137 patients with sudden onset headache, in 11 (8\%) onset was during sex, only 2 of whom had SAH [6].

In contrast to acute management, the optimal management of interval presentations of PHSA is not currently defined [7]. In the absence of evidence, some neurologists pursue a de facto policy of requesting non-invasive angiography, either magnetic resonance (MRA) or computed tomography (CTA), analogous to the investigation of suspected SAH presenting more than 10-14 days after the ictus when CT imaging to look for subarachnoid blood and lumbar puncture to look for xanthochromia are unlikely to be informative. The rationale of angiography is to identify an underlying cerebral aneurysm. Is such a policy of investigation justified? A study was undertaken to examine neuroimaging findings in late presentations of PHSA.

\section{Materials and methods}

All cases of PHSA seen by one consultant neurologist in general neurology outpatient clinics over a six-year period (2000-2005 inclusive) were identified. Case notes and neuroimaging were reviewed to ascertain demographics, details of clinical history, time from headache onset to referral, and neuroimaging findings. 


\section{Results}

Of 6019 consecutive new referrals seen, $25(0.42 \%)$ had a history compatible with PHSA [1]. All were referred by general practitioners. Time elapsed between most recent PHSA and referral was difficult to ascertain in many cases but where this could be estimated the range was 8 days to 10 weeks; no patient was seen in the outpatient clinic within 3 weeks of the last PHSA, ranging up to a maximum of 20 weeks. Four referral letters did not mention the relationship of headache to sexual activity.

The patients were similar to other cohorts of patients with PHSA [8] with respect to sex ratio ( $\mathrm{M}: \mathrm{F}=19: 6 ; 76 \%$ male), age range (19-56 years), mean $( \pm$ SEM) age (41.6 \pm 8.8 years) and PHSA subtype (preorgasmic:orgasmic=7:18). All patients were offered non-invasive angiography to exclude underlying aneurysm.

Nineteen patients (76\%) underwent neuroimaging $(\mathrm{M}: \mathrm{F}=14: 5$; preorgasmic: orgasmic=5:14), 18 with MRA, 1 with CTA. At this centre, both modalities are capable of resolving aneurysms of $2 \mathrm{~mm}$ diameter. All studies were normal.

\section{Discussion}

The place of angiography in acute presentation of PHSA is established, not only to identify headaches symptomatic of underlying aneurysm, but also to exclude a reversible angiopathy ("cerebral vasospasm"), which has been identified in some patients with acute PHSA [9] or recurrent thunderclap headache triggered by coitus [10]. Such findings may have implications for future treatment, including avoidance of potential vasoconstrictors such as medicines prescribed for rhinitis, SSRIs and recreational drugs such as cannabis. Hence early referral of patients with PHSA is required not only to exclude $\mathrm{SAH}(\mathrm{CT}, \mathrm{LP})$ but also to undertake angiography.

However, the place of angiography in late presentations of PHSA remains to be defined [7]. The current study, although subject to selection bias, because retrospective and hospital clinic-based, suggests that non-invasive angiography is normal and therefore not routinely indicated in late presentations of PHSA.

Acknowledgement Thanks to Julie Lyon, Sue Pritchard and Cheryl Whittingham-Jones for help with data retrieval.

\section{References}

1. International Headache Society Classification Subcommittee (2004)

The international classification of headache disorders, 2nd ed. Cephalalgia 24[Suppl 1]:1-160 [at 50-51]

2. Headache Classification Committee of the International Headache Society (1988) Classification and diagnostic criteria for headache disorders, cranial neuralgias and facial pain. Cephalalgia 8[Suppl 7]:1-96

3. Fisher CM (1968) Headache in cerebrovascular disease. In: Vinken PJ, Bruyn GW (eds) Headaches and cranial neuralgias. Handbook of clinical neurology, Vol 5. North Holland, Amsterdam, pp 124-156 [at 148]
4. Pascual J, Iglesias F, Oterino A, Vázquez Barquero A, Berciano J (1996) Cough, exertional and sexual headaches: an analysis of 72 benign and symptomatic cases. Neurology 46:1520-1524

5. Lance JW (1976) Headaches related to sexual activity. J Neurol Neurosurg Psychiatry 39:1226-1230

6. Landtblom AM, Fridriksson S, Boivie J, Hillman J, Johansson G, Johansson I (2002) Sudden onset headache: a prospective study of features, incidence and causes. Cephalalgia 22:354-360
7. Larner AJ (2006) Headache associated with sexual activity. Pract Neurol 6:134

8. Frese A, Eikermann A, Frese K, Schwaag S, Husstedt I-W, Evers S (2003) Headache associated with sexual activity: demography, clinical features, and comorbidity. Neurology 61:796-800

9. Valença MM, Valença LP, Bordini CA et al (2004) Cerebral vasospasm and headache during sexual intercourse and masturbatory orgasms. Headache 44:244-248

10. Ducros A, Sarov M, Berthet K et al (2004) Recurrent thunderclap headaches revealing reversible angiopathy of the central nervous system. Eur J Neurol 11[Suppl 2]:12-13 (abstract SC113) 